\title{
Modelling Capercaillie Tetrao urogallus lek sites distribution and their limiting factors in a central Norwegian managed forest landscape
}

\author{
Per Gustav Thingstad ${ }^{1 *}$, Marc Daverdin ${ }^{1} \&$ James D. M. Speed ${ }^{1}$ \\ ${ }^{1}$ Norwegian University of Science and Technology, NTNU University Museum, NO-7491 Trondheim, Norway. \\ *Correspondence: per.thingstad@ntnu.no
}

\begin{abstract}
Forest management has substantially altered Fennoscandian forests through clear-cutting practices started during the 1950s. Impacts on the natural biodiversity in mature boreal forest have been inevitable. The Capercaillie (Tetrao urogallus) is often regarded as an indicator species for natural old growth forest, displaying on traditional lek sites during spring. In a heterogeneous forest landscape of two adjoining municipalities in central Norway we studied whether forest management or other environmental factors can have influenced the lek distribution. We identified 15 active leks and 12 recently abandoned leks. The maximum entropy distribution modelling (MaxEnt) was used to investigate factors associated with lek distribution at two different scales, where the scale reflecting the lek site areas gave the most adequate result. Active leks were predominantly associated with mature stands of forest. In $65 \%$ of the study area the habitat suitability for lekking was most influenced by forest management. Furthermore, the recently abandoned leks were found less frequently in low productive and mature forests than the still active ones, implying that previous leks in productive forest stands may have been lost through logging. Based on our data we have developed models for the predicted distribution and the current limiting factors, showing that altered forest management could improve lek site suitability in large parts of this boreal forest.
\end{abstract}

Keywords: boreal forest, forest age, Capercaillie lek, forest productivity, habitat preference, limiting factor

The loss of natural habitats through human use is the dominant factor for the loss of biodiversity worldwide (e.g. Millennium Ecosystem Assessment 2005). In boreal forests a combination of taxon-specific management strategies might be required to sustain the natural biodiversity (Mönkkönen et al. 2014). However, birds and vascular plants seem in general to be better indicators and economically more efficient than other taxa for monitoring the preservation of the overall biodiversity in these landscapes (Juutinen \& Mönkkönen 2004), and in boreal forests, the Capercaillie is one of the most suitable indicator species (Suter et al, 2002, Pakkala et al. 2003, Segura et al. 2014, Mikoláŝ et al. 2015), especially at greater lek sites (Johansson \& Hellenberg 2017).

In Fennoscandia forestry has substantially changed the forest landscape over the last 50 to 60 years. New forest management practices, notably the increase in clear-cutting, have fragmented the boreal forest, and resulted in decreasing populations of a large number of plant and animal species (Essen et al. 1992, Edenius \& Sjöberg 1997, Thingstad et al. 2003). However, modern commercial forestry is also regulated. In Norway the Forestry Act («Skogbrukslova») and the Nature Diversity Act («Naturmangfoldlova»), are implemented to maintain the biological biodiversity in boreal forests, and the vitality of populations of naturally occurring species at a long-term scale. This may cause some conflicts between the commercial and conservation interests.

The western Capercaillie (Tetrao urogallus) prefers coniferous forests with extensive well-grown tree stands in the latest succession stages (Cramp \& Simmons 1980: 433, Saniga 2003). In the past it was distributed through most of the European boreal zone. Serious declines in western and central Europe populations during recent decades have resulted in local extinctions (Blair et al. 1997, BirdLife International 2016), and accordingly the Capercaillie is red-listed throughout many European countries (Storch 2001). Its present core area is within Fennoscandia and the western part of Russia.

The Capercaillie has a polygamous lek mating system. During spring time the birds display collectively at more or less traditional lek sites, surrounded by the males' day territories. Larger leks may require suitable daytime roosting areas up to one $\mathrm{km}$ from the lek centre (Rolstad \& Wegge 1987, Storch 1997, 2001, Kortland 2006), demonstrating the large-scale habitat requirements of this species. In forest management plans the Capercaillie should be given particular consideration within the nearest $300 \mathrm{~m}$ from the lek centres (Rolstad \& Andersen 2003).

In Norway a typical lek size is around 5 hectares 


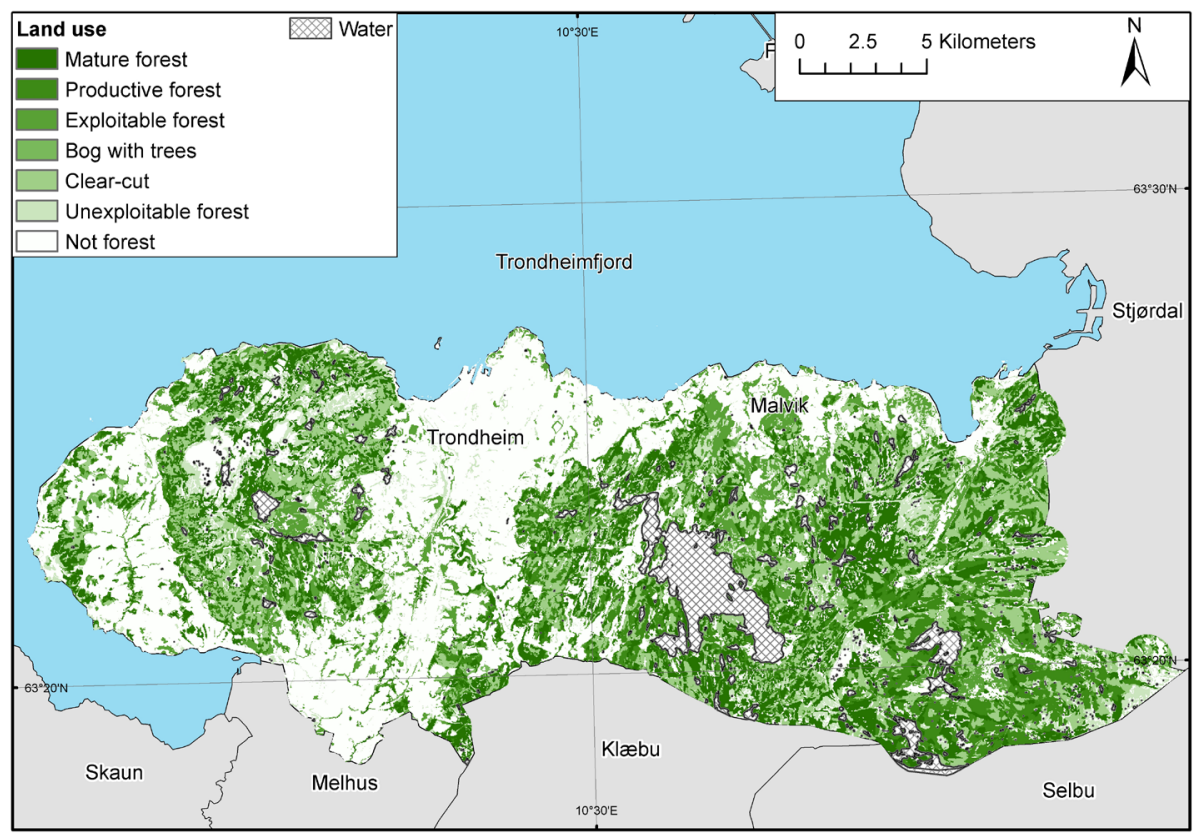

Figure 1. Map of study area showing the forest classifications. Non-forested land-covers (agricultural, urban etc.) are shown in white. As most forested areas in central Norway it shows a heterogeneous, fine-grained configuration.

(Rolstad \& Andersen 2003). These leks are typically spaced around $2 \mathrm{~km}$ apart in the boreal forest landscape (Wegge \& Rolstad 1986; Pakkala et al. 2003). The preferred vegetation types at the leks show some variations according to the geographic position, even though mature conifer forest with sufficient amount of bilberries (food), good shelter conditions and adequate overall forest cover in the immediate distance from the displaying area is of great importance (Gregersen \& Gregersen 2008, Johansson \& Hellenberg 2017). Today the areas covered by mature forest may be too sparse to explain the lekking-area persistence of the Capercaillie in many European areas where it still occurs (Quevedo et al. 2006, Sirkiä et al. 2011a). Thus, more recent studies have indicated that the forest structure is more important than the age of the forest, as leks are found within young and commercial forest with appropriate thinning as well (Stroch 2001, Miettinen et al. 2008, Watson \& Moss 2008, Sirkiä et al. 2010), inter alia in southeastern Norway (Rolstad \& Wegge 1987, 1989a,b, Rolstad 1991). Here some of the succeeding new plantations after the clear-cutting practice, which started in the 1950s, have now grown older (and are mostly over 30 years of age), and new leks have been reported to be established in these middle-age stands (Rolstad et al. 2007, Wegge \& Rolstad 2011).

In our study we aim to verify the current habitat preferences for the Capercaillie's lek sites and their surroundings in an active heterogeneous managed boreal forest landscape in central Norway, where there is a significant amount of young and middleage forest. Given the disclosed preferences we would produce models for the predicted distribution of leks and their most important daytime areas. Finally, but not least important, we try to give a model for the limiting factors given the current situation. This approach can hopefully be transformed to management actions which can maintain and even improve the preferred habitat for the Capercaillie over a larger landscape scale.

\section{METHODS}

\section{Lek survey}

Over the last seven years (2009-2015) we collated information spanning two decades and surveyed all known Capercaillie leks in Trondheim (the old delimitation without Klæbu) and Malvik municipalities in central Norway (data sources are given in the Acknowledgements). These municipalities, which have a total land area of approximately $510 \mathrm{~km}^{2}$, have a considerable proportion of conifer forest with different degrees of commercial timber harvesting and suitability for the Capercaillie (about $300 \mathrm{~km}^{2}$; Figure 1). We visited all known lek localities for at least one night during the optimal displaying period (late April to early May). During the same period we also surveyed the wider forest landscape for signs of further leks (in periods with snow on the ground). In total 27 lek sites were identified as being active at some point over the last three decades; 15 of these were found to be currently active (displaying cocks registered during the survey periods) and 12 have been totally abandoned or have collapsed ("NA-leks" and previous large leks that are now at most supporting a solitary male; cf. Table 1). The localities of the leks in this study are intentionally withheld due to conservation and ethical concerns. 


\section{Environmental data}

Spatial topographical and forest structure data were collected for the two municipalities of Trondheim and Malvik. These are summarised in Table 2. A digital elevation model was obtained from the Norwegian Mapping Authority and the variables elevation (m), slope (degrees) and aspect (four cardinal categories $\mathrm{N}$, $\mathrm{E}, \mathrm{S}$ and $\mathrm{W}$ facing) were used in subsequent analyses. Forest productivity maps were obtained from the Norwegian Mapping Authority where forest stands are classified as unproductive, low productivity, medium productivity or high productivity (Table 3). Forest cutting class (successional stage since clear cutting) was classified on the basis of municipality forest management records, updated in 2008 (Trondheim) and 1999-2006 (Malvik). The forests were classified according to time since clear-cutting (3 categories) adjusted for the forest productivity (4 categories including unproductive). We updated this information where more recent clear cuts were observed at the leks and in the immediate surroundings. The total coverage of the forest types and their distribution within the four different productivity classes is provided in Table 4. Consequently, the forest classifications should correspond with the actual conditions at the lek sites during our registration period. As two Capercaillie leks were found very close to the border between Malvik and the neighbouring municipality (Stjørdal) the study area and environmental variables were extended one $\mathrm{km}$ beyond the municipality boundary in these regions.

\section{Distribution modelling}

Capercaillie leks occur infrequently within the landscape. We therefore used the MaxEnt approach to investigate the distribution of Capercaillie leks within our study area (Elith et al. 2011). MaxEnt was selected since it has been shown to be amongst the best performing distribution modelling approaches, particularly at low sample sizes (Hernandez et al. 2006, Pearson et al. 2007, Wisz et al. 2008).

A Capercaillie lek usually covers relatively large areas. To reflect this all the environmental variables were aggregated from a $25 \times 25 \mathrm{~m}$ grid to a $250 \times 250$ $\mathrm{m}$ grid (lek scale) and a $600 \times 600 \mathrm{~m}$ grid (daytime areas scale reflecting the most important surrounding habitats of a lek). The mean value of aggregated cells was calculated for continuous variables, and the modal value (most frequent) for categorical variables.

The random selection of background environmental points was limited to regions with forest cover (the coloured areas in Figure 1). The MaxEnt logistic output for active lek presence at ordinary occurrence points was set to 0.5 (Elith et al. 2011). The model was cross-validated by dividing the dataset into 5 sets and training with four sets and testing with the remainder,
Table 1. The status of the surveyed leks in Malvik (M) and Trondheim (T). Status: $\mathrm{L}=$ large ( $>5$ displaying cocks), $\mathrm{M}=$ medium (2-5 displaying cocks), $\mathrm{S}=$ solitary (one displaying cock over a longer time period), $\mathrm{A}=$ abandoned (since 2000, older information not used, may involve solitary male some years after a collapse). Checked $=$ our (including Almestad) control years of the leks; in brackets checked by others. NA $=$ not active the last decade according to given information.

\begin{tabular}{|c|c|c|}
\hline Lek number & Status & Checked \\
\hline M1 & M & 2009,2010 \\
\hline M2 & $\mathrm{L}$ & 2009,2012 \\
\hline M3 & $\mathrm{L}$ & 2009 \\
\hline M4 & M & 2009,2012 \\
\hline M5 & $\mathrm{L}$ & 2007,2011 \\
\hline M6 & $\mathrm{L}$ & 2009 \\
\hline M7 & M & 2009,2012 \\
\hline M8 & $\mathrm{L}$ & 2010,2011 \\
\hline M9 & A & 2011 \\
\hline M10 & $\mathrm{S}$ & 2012 \\
\hline M11 & A & 2012 \\
\hline M12 & A & NA \\
\hline M13 & A & NA \\
\hline M14 & A & $(2002)$ \\
\hline M15 & A & NA \\
\hline $\mathrm{T} 1$ & $\mathrm{~L}$ & 2011, 2012-2015 \\
\hline $\mathrm{T} 2$ & M & 2010,2011 \\
\hline $\mathrm{T} 3$ & A & 2009,2010 \\
\hline $\mathrm{T} 4$ & M & $2010,2011-2013$ \\
\hline T5 & M & $2010,2012-2015$ \\
\hline T6 & A & 2009,2010 \\
\hline $\mathrm{T} 7$ & A & NA \\
\hline $\mathrm{T} 8$ & A & NA \\
\hline T9 & $\mathrm{S}$ & 2011,2012 \\
\hline $\mathrm{T} 10$ & M & 2015 \\
\hline T11 & A & $(2003), 2014,2015$ \\
\hline T12 & A & $(2002), 2011$ \\
\hline
\end{tabular}

and replicating this process five times. Response curves and percentage contributions of all variables were calculated as the mean ( \pm standard deviation) from each of the five replicate runs. Predictions from the model were made across the whole (forested) study area. We also identified the factor limiting the probability of lek occurrence at each point across the study area using a limiting factors analysis; limiting factor analysis identifies the single variable that most influences model predictions at each cell across the study region (Elith et al. 2010). The final model predictions and the limiting factor maps were disaggregated back to $25 \times 25 \mathrm{~m}$ and masked by forest cover at the original $25 \times 25 \mathrm{~m}$ resolution to ensure that the model predictions were not extended beyond the range of forest land cover. Note that our approach identifies habitat suitability for lek locations, but due to the spatial segregation of lek sites, it does not allow us to estimate potential lek density 
Table 2. The variables used in modelling the features of the Capercaillie's preferred habitat types in Trondheim and Malvik. Four productivity categories are given: Unproductive $=<1 \mathrm{~m}^{3}$ increment per ha and year, Low productivity $=1-3 \mathrm{~m}^{3}$ increment per ha and year, Medium productivity $=3-5 \mathrm{~m}^{3}$ increment per ha and year, and High productivity $=5-10 \mathrm{~m}^{3}$ increment per ha and year.

\begin{tabular}{|c|c|c|c|}
\hline Variable & Structure & Details & Source \\
\hline $\begin{array}{l}\text { Forest classification (cutting } \\
\text { class) }\end{array}$ & $\begin{array}{l}\text { Clear cuts/young recruiting } \\
\text { stands } \\
\text { Middle-age stands } \\
\text { Mature forest stands } \\
\text { Unclassified exploitable } \\
\text { forests } \\
\text { Commercially unexploitable } \\
\text { forests } \\
\text { Bogs covered with scattered } \\
\text { trees }\end{array}$ & $\begin{array}{l}\text { Categorical } \\
25 \times 25 \mathrm{~m} \\
\text { Non forest land-cover was } \\
\text { set to NA }\end{array}$ & $\begin{array}{l}\text { Municipality forest } \\
\text { management } \\
\text { Trondheim (2008) } \\
\text { Malvik (1999-2006) }\end{array}$ \\
\hline Forest productivity & $\begin{array}{l}\text { Unproductive } \\
\text { Low productivity } \\
\text { Medium productivity } \\
\text { High productivity }\end{array}$ & $\begin{array}{l}\text { Categorical } \\
25 \times 25 \mathrm{~m} \\
\text { Non forest land-cover was } \\
\text { set to NA }\end{array}$ & $\begin{array}{l}\text { The Norwegian Mapping } \\
\text { Authority "Norge digital" } \\
\text { Trondheim (1963-2006) } \\
\text { Malvik (1963-2007) }\end{array}$ \\
\hline Elevation & m a.s.l. & $\begin{array}{l}\text { Continuous } \\
25 \times 25 \mathrm{~m}\end{array}$ & $\begin{array}{l}\text { The Norwegian Mapping } \\
\text { Authority "Norge digital" }\end{array}$ \\
\hline Slope & Degree & $\begin{array}{l}\text { Continuous } \\
25 \times 25 \mathrm{~m}\end{array}$ & $\begin{array}{l}\text { The Norwegian Mapping } \\
\text { Authority "Norge digital" }\end{array}$ \\
\hline Aspect & $\begin{array}{l}\text { North facing } \\
\left(\text { aspect }<45^{\circ} \text { or aspect } \geq\right. \\
\left.315^{\circ}\right) \\
\text { East facing } \\
\left(45^{\circ} \leq \text { aspect }<135^{\circ}\right) \\
\text { South facing } \\
\left(135^{\circ} \leq \text { aspect }<225^{\circ}\right) \\
\text { West facing } \\
\left(225^{\circ} \leq \text { aspect }<315^{\circ}\right)\end{array}$ & $\begin{array}{l}\text { Converted to categorical } \\
25 \times 25 \mathrm{~m}\end{array}$ & $\begin{array}{l}\text { The Norwegian Mapping } \\
\text { Authority "Norge digital" }\end{array}$ \\
\hline
\end{tabular}

across the study region.

Data were processed and analysed in the $\mathrm{R}$ statistical environment ( $R$ Core Team 2014), using the packages 'raster' (Hijmans 2015) and 'dismo' (Hijmans et al. 2014). Maxent version 3.3.3k was used to develop the MaxEnt models (Phillips et al. 2004; Phillips et al. 2006, https://www.cs.princeton. edu/ schapire/maxent/). MaxEnt was tuned using the package EMNeval (Muscarella et al. 2014). Models were run with regularization parameters between 0.5 and 4.0 (increasing in steps of 0.5 ) and allowing either linear, hinge, linear + quadratic, linear + quadratic + hinge, linear + quadratic + hinge + product and linear + quadratic + hinge + product + threshold features. The selected model included the parameter combinations that provided the minimum AICc value: that was regularization parameter of 2.5 and allowing linear and quadratic features only (Supplementary Figure S1). Finally, we extracted the environmental data for all lek sites and used t-test (continuous variables) and Fisher's exact test (categorical variables) to test whether abandoned and active leks differed in environmental characteristics.

\section{RESULTS}

We surveyed a total of 27 lek localities (Table 1). Of these, 15 were active (status L, M or S) with at least one displaying male observed on at least one occasion during our inspections in the period 2009 to 2015, while 12 had been totally abandoned or collapsed since 2000 .

At the lek scale $(250 \times 250 \mathrm{~m})$, the relative suitability for lek occurrence was higher in mature forests than in any other forest type (Figure 2a). It was also higher in low productivity forests than unproductive forests, or medium or high productivity forests (Figure $2 b$ ). The relative occurrence of leks was highest in north facing sites (Figure 2c), and increased with elevation up to certain levels (Figure 2d). Slope was indifferent (Figure 
Table 3. The forest classification in relation to productivity and age, and a further explanation of the used forest classification parameters.

\begin{tabular}{|c|c|c|c|}
\hline Forest type & Forestry classification & Productivity & Age of trees \\
\hline $\begin{array}{l}\text { Clear cut/young } \\
\text { recruiting forest }\end{array}$ & Cutting class 1 and 2 & $\begin{array}{l}\text { High } \\
\text { Medium } \\
\text { Low }\end{array}$ & $\begin{array}{l}<24 \text { years } \\
<34 \text { years } \\
<44 \text { years }\end{array}$ \\
\hline Middle-age forest & Cutting class 3 & $\begin{array}{l}\text { High } \\
\text { Medium } \\
\text { Low }\end{array}$ & $\begin{array}{l}25-54 \text { years } \\
35-69 \text { years } \\
45-74 \text { years }\end{array}$ \\
\hline Mature forest & Cutting class 4 and 5 & $\begin{array}{l}\text { High } \\
\text { Medium } \\
\text { Low }\end{array}$ & $\begin{array}{l}>55 \text { years } \\
>70 \text { years } \\
>75 \text { years }\end{array}$ \\
\hline $\begin{array}{l}\text { Unclassified exploitable } \\
\text { forest }\end{array}$ & $\begin{array}{l}\text { Unclassified forest with unknown cutting class, } \\
\text { but presumed to be of commercial interest }\end{array}$ & & \\
\hline $\begin{array}{l}\text { Commercially } \\
\text { unexploitable forest }\end{array}$ & $\begin{array}{l}\text { Unclassified forest with unknown cutting class } \\
\text { and too low forestry productivity to be of } \\
\text { commercial interest }\end{array}$ & & \\
\hline Bog with trees & $\begin{array}{l}\text { Bogs covered with scattered trees (especially } \\
\text { pines) }\end{array}$ & & \\
\hline
\end{tabular}

Table 4. The area (in $\mathrm{km}^{2}$ ) in Trondheim and Malvik of the different forest types (cf. Table 3) according to productivity classification.

\begin{tabular}{|c|c|c|c|c|c|}
\hline $\begin{array}{l}\text { Forest type/ } \\
\text { productivity }\end{array}$ & Unprod. & Low prod. & Medium prod. & High prod. & Sum \\
\hline Clear cut/young ........................ & 2.8 & 18.9 & 31.0 & 15.6 & 68.4 \\
\hline Middle-age ....................................... & 2.8 & 14.6 & 21.9 & 14.8 & 54.1 \\
\hline Mature & 5.6 & 46.2 & 27.7 & 12.5 & 92.1 \\
\hline Exploitable ............................. & & & 22.4 & 21.8 & 44.2 \\
\hline 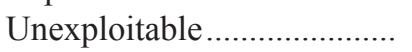 & 13.7 & 21.8 & & & 35.4 \\
\hline Bog with trees .......................... & 5.3 & 1.1 & 0.3 & 0.3 & 6.8 \\
\hline 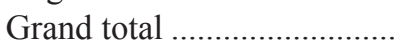 & 30.3 & 102.6 & 103.3 & 64.8 & 301.1 \\
\hline
\end{tabular}

2e). Forest classification was the dominant factor in the model (Figure $2 \mathrm{f})$, contributing $75.2 \%( \pm 15.2)$ to the full model, followed by forest productivity $(16.3 \%$ $\pm 17.4)$. The topographical variables aspect $(5.4 \% \pm$ 4.2) and elevation $(3.0 \% \pm 2.5)$ contributed less to the model, and slope did not contribute at all $(0 \%)$. The area under the receiver-operating characteristic curve (AUC) for the MaxEnt model presented here was 0.886 $(\mathrm{SD}=0.052)$, where a value of 0.5 indicates a model performing at random and a value approaching 1.0 indicates perfect discrimination between presence and background points in the model validation.

At the daytime area scale $(600 \times 600 \mathrm{~m})$ forest productivity was the dominant variable in contributing to the model of lek distribution $(81.7 \% \pm 9.0)$. Lek suitability at this scale was greatest again within low productive and mature forests and at high elevations (Figure 3). The mean AUC for the surrounding habitat model was $0.82(\mathrm{SD}=0.095)$.

According to the lek scale analysis only a low proportion (19\%) of the forested area of Trondheim and Malvik had a relative occurrence rate of greater than $0.5\left(57.4 \mathrm{~km}^{2}\right.$, Figure 4a, Figure 5). Forest classification (cutting class) limited lek occurrence in the majority $(64.7 \%)$ of the forested areas $\left(195.8 \mathrm{~km}^{2}\right.$, Figure $4 \mathrm{~b}$, Figure 6). The topographical variables (aspect and elevation) together were the main limiting factors of lek occurrence in $20.0 \%\left(60.5 \mathrm{~km}^{2}\right)$ of the forested area (Figure $4 \mathrm{~b}$ ), and forest productivity limited lek occurrence in a further $15.3 \%\left(46.2 \mathrm{~km}^{2}\right)$ of the study area (Figure 4b). Patches of forest where lek occurrence was limited most by forest classification had a lower relative lek occurrence rate than where lek occurrence was limited by other factors (Figure 4c).

On average the active lek sites consist of $58.4 \%( \pm$ 22.0) mature forest, while the abandoned ones consist of $30.7 \%( \pm 27.5)$ mature forest; the mean value for our forested study area is $30.6 \%$. At the larger spatial scale (daytime areas), forest productivity seemed to be limiting the habitat suitability for total lek areas in 

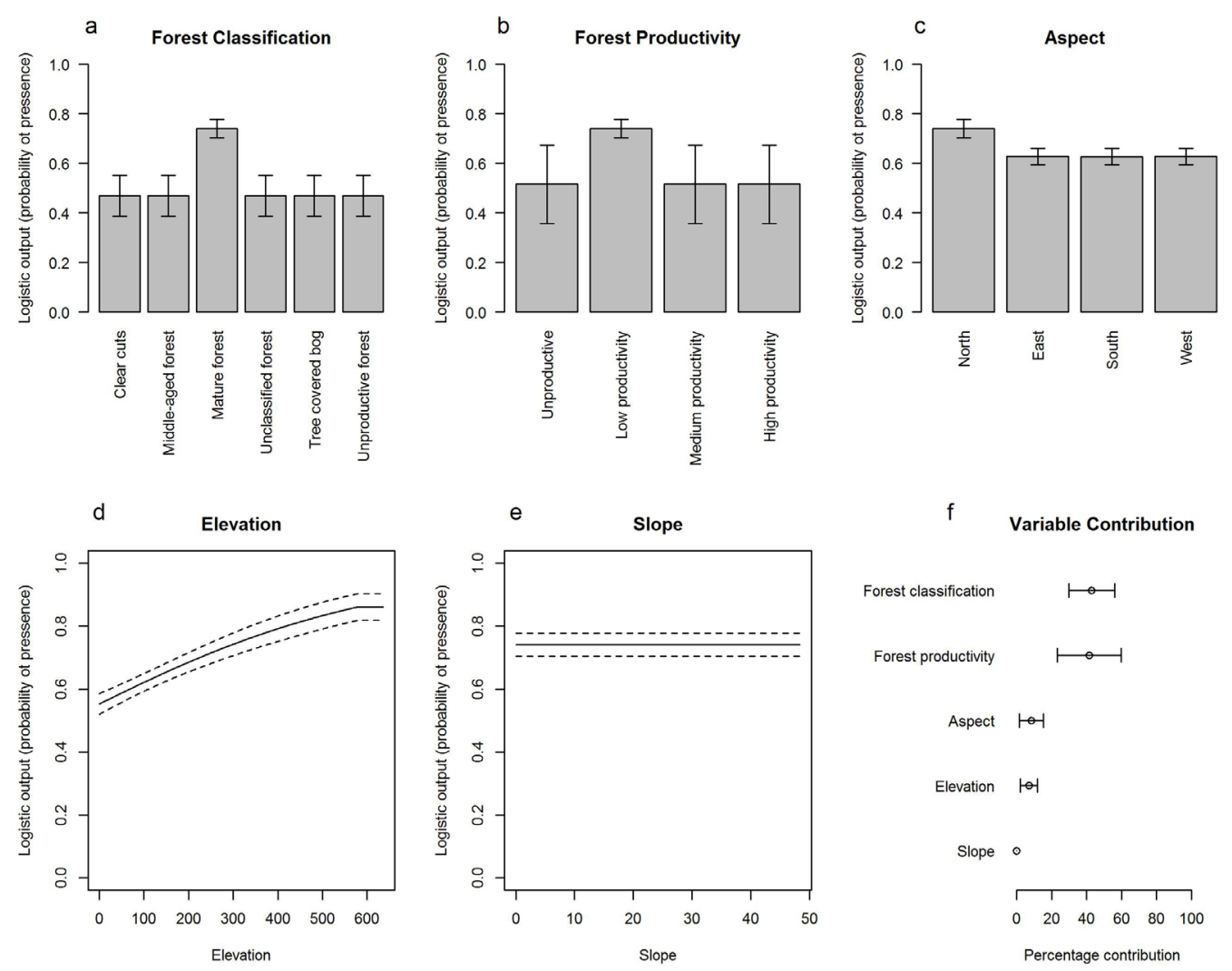

Figure 2. (a-e): Response curves for the MaxEnt capercaillie lek distribution model at the lek area scale $(250 \mathrm{~m} \mathrm{x} 250 \mathrm{~m})$. The logistic output for each variable is shown with standard deviation estimated from a five-fold cross-validation. The predictions are estimated by varying each variable whilst leaving the remaining variables at their average value. Variables are ordered (a-e) according to how strongly they contribute to the overall model. (f): The percentage contribution to the overall model (mean \pm standard deviation) for each variable.
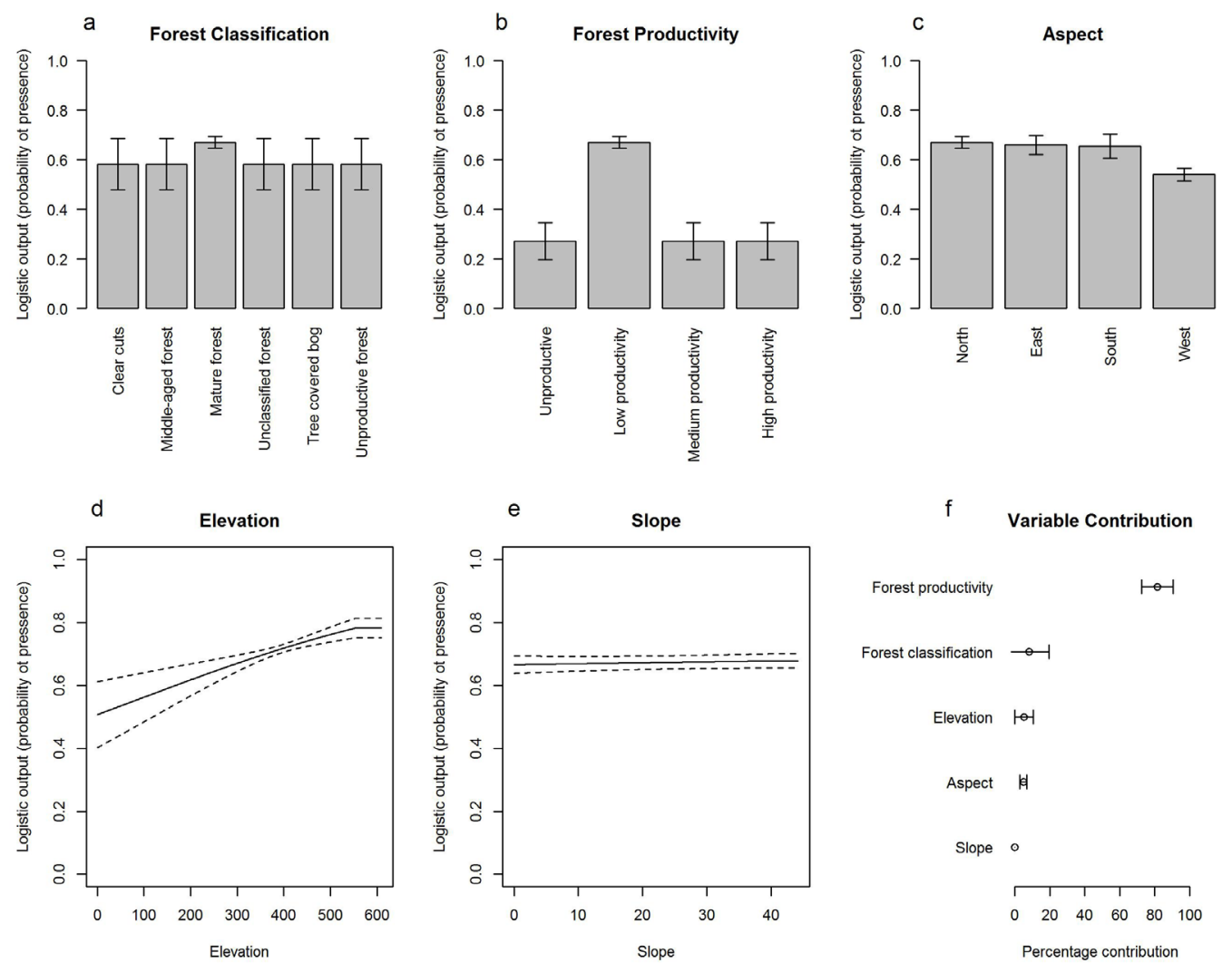

Figure 3. Response curves for the MaxEnt capercaillie lek distribution model at the daytime area scale (600 m x $600 \mathrm{~m})$. See text to Figure 2 for further explanations. 


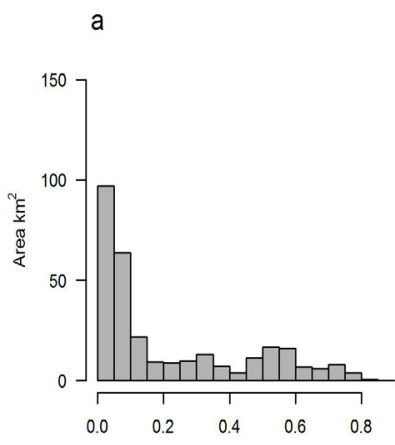

Probability of lek occurrence

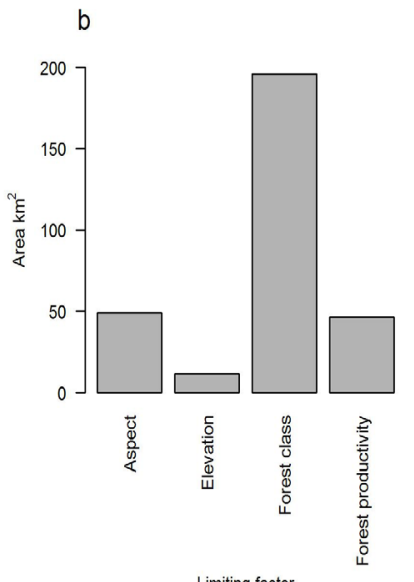

Limiting factor
C

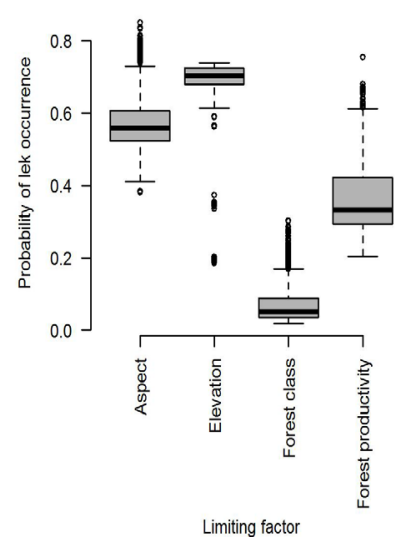

Figure 4(a) Distribution of lek occurrence probabilities in the forests of Trondheim and Malvik (showing the area of each lek occurrence probability) and (b) the area of forest where the probability of lek occurrence was limited by each environmental variable. (c) the distribution of lek occurrence probabilities where the probability of occurrence was limited by a given variable. The thick lines show the median value, the box the upper and lower quartiles and the whiskers extend up to 1.5 times the interquartile range with values beyond this range shown as outlying points.

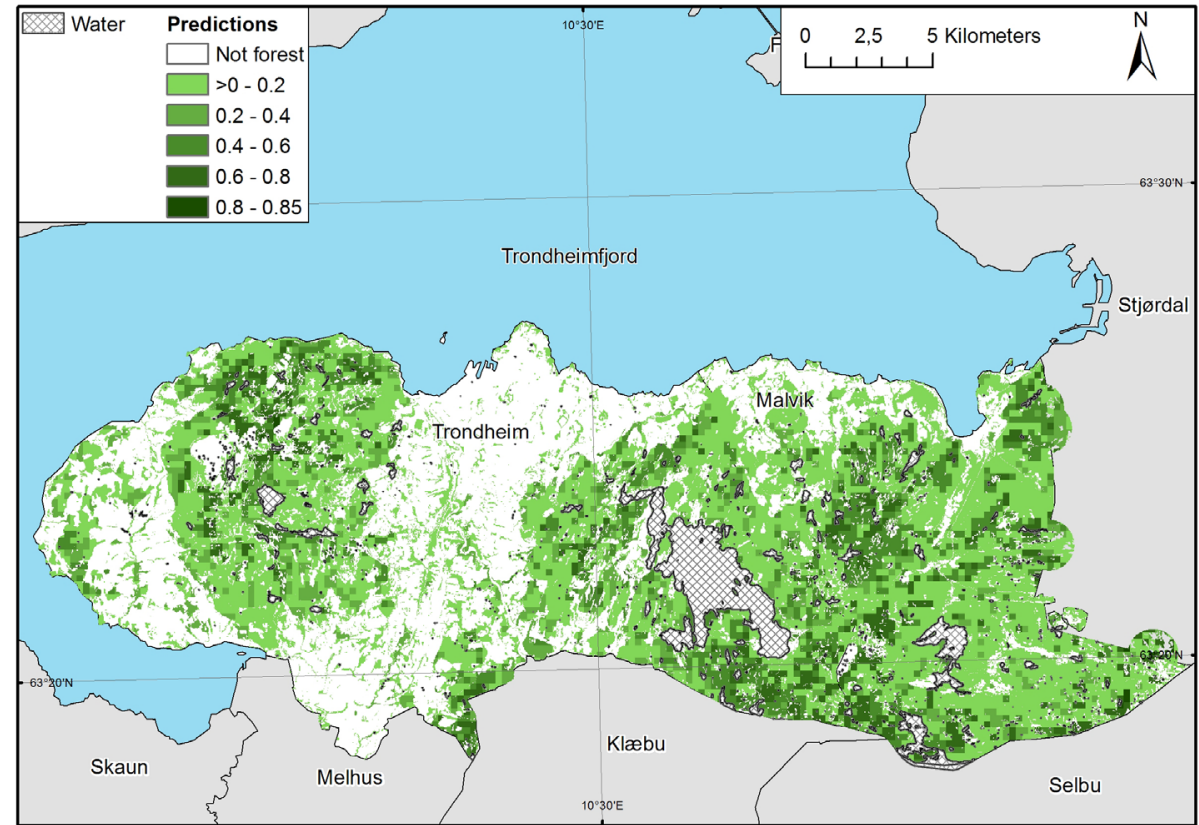

Figure 5. Predicted distribution of capercaillie leks within the forests of Trondheim and Malvik municipalities, mid-Norway. Non-forested land-covers (agricultural, urban etc.) are shown in white.

the majority $(61.5 \%)$ of the study forest area (Figure 7). Forest classification was the limiting factor in only $13.5 \%$ of the study area at this scale (Figure 7). Abandoned leks were registered less frequently than active leks in low productivity forests (Fisher's exact test $p=0.035$, Figure $8 \mathrm{a}$ ), and more frequently at clear-cuts/young stands and middle-age forest stands (Fisher's exact test $p=0.006$, Figure $8 b$ ). Active and abandoned leks did not differ in terms of aspect, slope or elevation $(p>0.05$, Figure $8 c-e)$.

\section{DISCUSSION}

In this study we examined predictors of the geographic distribution of Capercaillie leks in the managed boreal forests in two central Norwegian municipalities. We found that forest classification was the dominant factor in predicting the occurrence of Capercaillie leks at the lek area scale in these forests, and that forest management limited the suitability of forest for lek occurrence over the majority of the forested area. The 


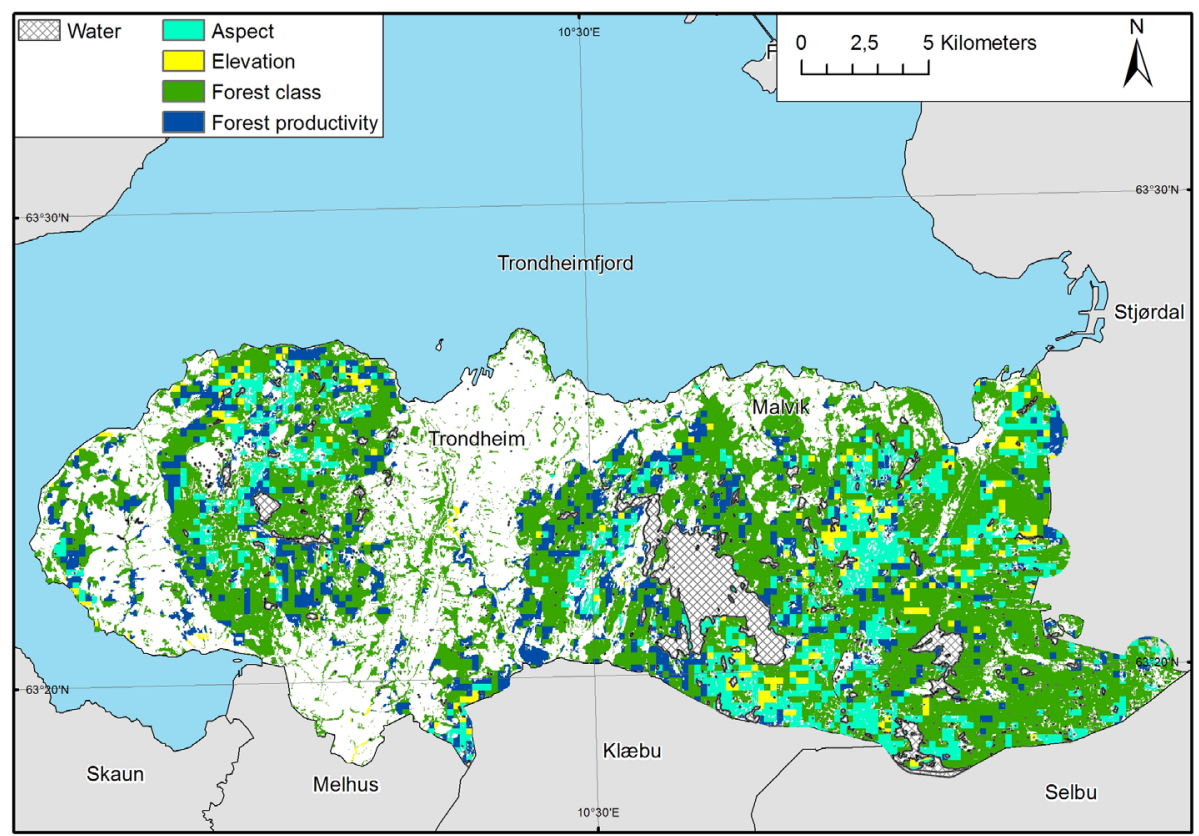

Figure 6. Limiting factors map showing the variable that most affects the model prediction for a given point across the study area. Non-forested land-covers (agricultural, urban etc.) are shown in white.

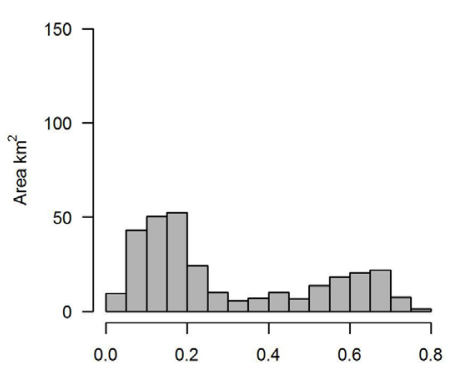

Probability of lek occurrence b

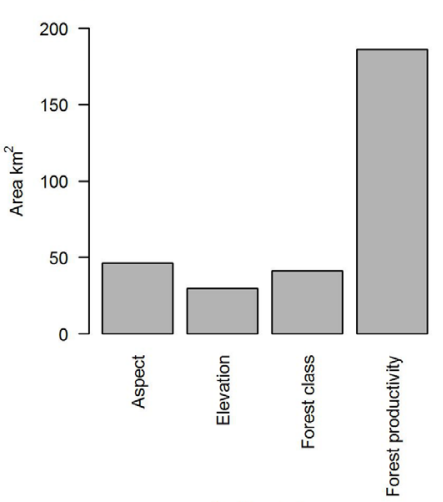

Limiting factor

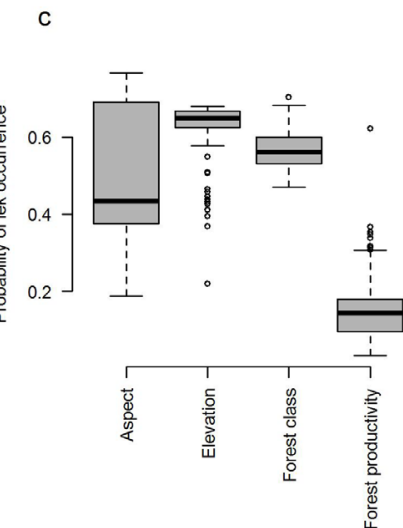

Limiting factor

Figure 7. a) Distribution of lek occurrence probabilities in the forests of Trondheim and Malvik by use of the daytime scale (showing the area of each lek occurrence probability) and (b) the area of forest where the probability of lek occurrence was limited by each environmental variable at the same scale. (c) the distribution of lek occurrence probabilities where the probability of occurrence was limited by a given variable. See text to Figure 4 for further information.

presence of leks was associated with the location of mature forest stands. At the daytime area scale forest productivity seemed to be the limiting factor with highest relative occurrences in low productive forests. The forest landscape in our study area is naturally quite heterogeneous and has a spatial fine-grained configuration, thus normally containing a certain portion of mature forests at greater scales, which may obscure the Capercaillie dependence of mature forest at our daytime area scale. Moreover, our registered 12 abandoned leks were better represented in productive forest and early successional stages following clear cutting than currently active leks. This indicates that it is not necessarily the Capercaillie preference that excludes leks in more productive forests, but rather the forestry prevalence for logging the most profitable stands and thereby leaving too little areas with mature forest on more productive soils.

Given the normally small-scaled habitat mosaic in the central Norwegian boreal forest landscape, the habitat requirements under other phases of the Capercaillie life story will normally not be a limiting factor for a vigorous population. Therefore, the focus of our findings will be upon those detected on the lek area scale, as they represent a foundation for adequate forest management guiding. 

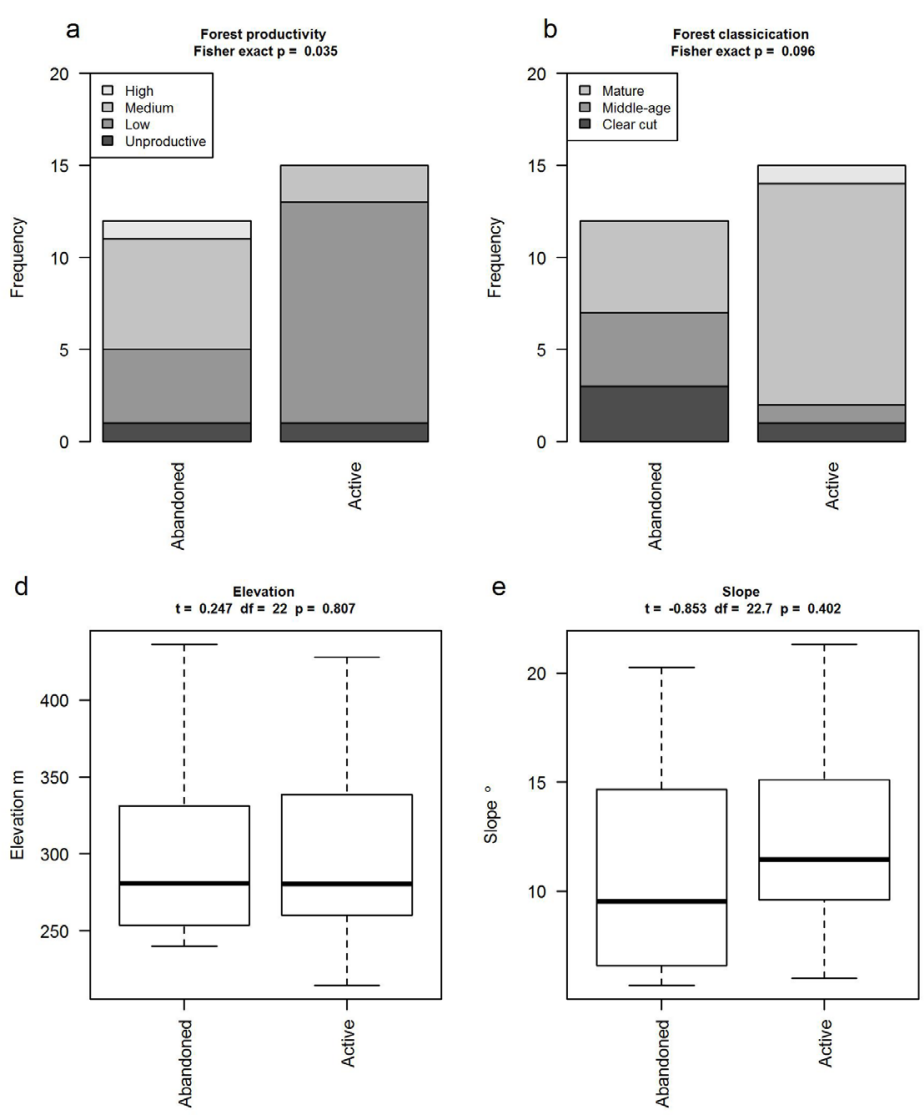

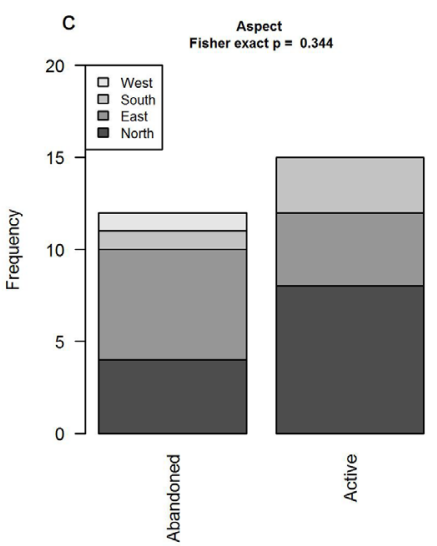

Figure 8. Figures comparing environmental variables (a forest productivity, $\mathrm{b}$ forest classification, c aspect, d elevation and e slope) in active and abandoned leks. Fisher's exact test was used to test the independence of class of categorical variables with lek status (a-c), and tests to test whether the mean values for continuous variables differed with lek status (d-e).
In Norway, clear-cutting has been widespread for several decades (more than 50 years). In some regions Capercaillie leks have now become established in secondary successional productive plantation forests (Rolstad et al. 2007, Wegge \& Rolstad 2011), and they can show some flexibility when their lek areas are clear-felled by searching for new suitable lek sites in the surroundings, and to some extent they are even capable of adapting to new conditions (Ringaby 2014). It is likely that the many forest stands formed through secondary succession on previous clear-cuts have developed into stands with too dense tree cover, as they have not passed through the requisite advanced thinning practice (Miettinenen et al. 2008, 2009, Lakka \& Kouki 2009, Wegge \& Rolstad 2011). We found no evidence for active lek occurrence being associated with forest stands in the middle-age stage in our area. However, small patches of clear-cut forests may mimic the Capercaillie's original preferences toward more open elevated forest intermingled with bogs and glades (Juana 1994, Hjort 1996), and such small clear-cuts were associated with some of our active lek sites. The canopy cover as well as the horizontal cover close to ground might be of more importance than the age of the forest (Miettinen et al. 2010). Anyhow, as long as the forested landscape still contains a sufficient proportion of mature and/or "structurally suitable" forest, Capercaillie should be able to persist within these central Norwegian boreal forest landscapes (cf.
Ringaby 2014). As isolated forest fragments smaller than 100 ha are not suitable for the Capercaillie (e.g. González et al. 2012), such patches of forest can be excluded from this management regime.

Forest classification (i.e. stage following clearcutting) limits the occurrence of leks within as much as $196 \mathrm{~km}^{2}(65 \%)$ of the study region. In these areas alternative management regimes could increase the suitability of forest for Capercaillie leks. The most obvious one is to allow a greater proportion of forest stands to reach and stay in the preferable mature stage, but this is not necessarily an economically sustainable approach. For the benefit of Capercaillie, it is important to manage the forest in such a way that it allows the forest stands to succeed with multiple tree layers and adequate canopy cover as well as cover close to ground (Miettinen et al. 2009, 2010). Simultaneously the tree density should be prevented from becoming too high, as in many younger plantations where a dense and uniform tree layer reduces the outlook and represents a flying obstruction for the Capercaillie (Finne et al. 2000). This advanced thinning practice (Rolstad \& Andersen 2003, Miettinenen et al. 2008, 2009, Lakka \& Kouki 2009; Wegge \& Rolstad 2011) needs to be implemented to greater extent and on earlier successional stages than under the past regimes.

In this study we have demonstrated that forest age is the main determinant of forest habitat suitability for Capercaillie lek occurrence, and that forest management 
is the factor that has reduced the suitability of forest for lekking over the majority of the forested area in our study region. Within the northern Finnish boreal forests Miettinenen et al. (2009) noticed a shift in the Capercaillie preference from mature stands during 1989-1992 to a positive association with younger advanced thinning stands during 2000-2003. However, so far we have not found evidence of such a shift in our study area.

Our findings suggest that there is a potential to strengthen the current Capercaillie population significantly, as we find a large area where an altered forest management could improve the suitability for lek sites. This presumes a forest management regime that is better adjusted to the habitat requirements for the Capercaillie. By doing that, since the Capercaillie is an umbrella species (Suter et al. 2002, Pakkala et al. 2003), the overall biodiversity of the natural boreal forests should also be better maintained, and thereby fulfil the objectives of relevant legislation (e.g. the Nature Diversity and Forestry Acts). The limiting factors map could be used as a tool for the local forestry, e.g. showing areas where they should perform the necessary thinning practice for achieving forest with qualities for Capercaillie and forestry economy in the future. However, leaving sufficient forest areas to reach and stay in the mature phase until new stands can achieve the adequate successional stages will be of most importance for the local Capercaillie populations. Hopefully, given the use of the recommended thinning regime, some of the middle-age forest stage might also provide the right conditions for lek performance of the Capercaillie in central Norwegian boreal forest landscapes in the future. Given those conditions, we then may log some of the current remaining old growth forest stands within the Capercaillie habitat (at the daytime area scale) without affecting the local Capercaillie populations.

Acknowledgements. We highly appreciate the efforts from all those who assisted us during the fieldwork, checking known localities and searching for new leks. Of particularly great value has been the information given from both the involved municipalities' forest and wildlife authorities. Here we particularly thank Stian R. Almestad for updated information about the lek status in the Malvik municipality, and Morten Haugen and Espen Bråthen for the collaboration in Trondheim. We have also collected and controlled useful information from different people using these forests as their recreation area. We are further thankful to Trondheim and Malvik municipality offices for giving the necessary permission to use the updated municipality forestry maps, showing the current distribution of the different cutting classes of the forest in the actual landscapes. We also highly appreciate some remarks of great value from knowledgeable colleagues.

\section{REFERENCES}

BirdLife International. 2016. Tetrao urogallus. The IUCN Red List of Threatened Species 2016: e.T22679487A85942729. http://dx.doi.org/10.2305/ IUCN.UK.2016-3.RLTS.T22679487A85942729.en. Downloaded on 30 April 2018.

Blair, M., Bijlsma, R. \& Hagemeijer, W. 1997. The EBCC atlas of European breeding birds. London: T. \& A. D. Poyser.

Cramp, S. \& Simmons, K.E.L. (eds.) 1980. The birds of the Western Palearctic. Vol. II. Oxford Univ. Press, Oxford.

Edenius, L. \& Sjöberg, K.1997. Distribution of birds in natural landscape mosaics of old-growth forests in northern Sweden: relations to habitat area and landscape context. Ecography 20: 425-431.

Elith, J., Kearney, M. \& Phillips, S. 2010. The art of modelling range-shifting species. Methods in Ecology and Evolution 1: 330-342.

Elith, J., Phillips, S.J., Hastie, T., Dudík, M., Chee, Y.E. \& Yates, C.J. 2011. A statistical explanation of MaxEnt for ecologists. Diversity and distributions 17: 43-57.

Esseen, P.-A., B. Ehnström, L. Ericson \& Sjöberg, K. 1992. Boreal forest - the focal habitats of Fennoscandia. Pp. 252-325 in L. Hansson (ed.). Ecological principles of nature conservation. Elsevier Applied Science, London.

Finne, M.H., Wegge, P., Eliassen, S. \& Odden, M. 2000. Daytime roosting and habitat preference of capercaillie Tetrao urogallus males in spring - the importance of forest structure in relation to anti-predator behaviour. Wildlife Biology 6: 241-249.

González, M-A., Olea, P.P., Mateo-Tomás, P., García-Tejero, S., de Frutos, A., Robles, L., Purroy. F.J. \& Ena, V. 2012. Habitat selection and diet of western capercaillie Tetrao urogallus in an atypical biogeographical region. Ibis 154: 260-272.

Gregersen, H. \& Gregersen, F. 2008. Old bilberry forest increases likelihood of capercaillie (Tetrao urogallus) lek occupancy in Southern Norway. Ornis Norvegica 31: 105-115.

Hernandez, P.A., Graham, C.H., Master, L.L. \& Albert, D.L. 2006. The effect of sample size and species characteristics on performance of different species distribution modeling methods. Ecography 29: $773-$ 785.

Hijmans, R.J. 2015. Raster: Geographic data analysis and modeling. R package version 2.3-24.

Hijmans, R.J., Phillips, S., Leathwick, J. \& Elith, J. 2014. Dismo: Species distribution modeling. $\mathrm{R}$ package version $1.0-5$.

Hjorth, I. 1996. Storfugl - tiur og røy. Naturforlaget. (In Norwegian)

Johansson, C. \& Hellenberg, J. 2017. Tjädern - En kunskapssammanställning. Sveriges Ornitologiska Förening - Birdlife Sverige. (In Swedish)

Juana, E. de 1994. Family Tetraonidae (Grouse). Pp. 376410 in Hoyo, J. del, Elliott, A. \& Sargatal, J. (eds.). 
Handbook of the Birds of the World. Vol. 2. New World Vultures to Guineafowl. Lynx Edicions, Barcelona.

Juutinen, A. \& Mönkkönen, M. 2004. Testing alternative indicators for biodiversity conservation in old-growth boreal forests: ecology and economics. Ecological Economics 50: 35-48.

Kortland, K. 2006. Forest management for capercaillie. Bocklet, Capercaillie BAP Group.

Lakka, J. \& Kouki, J. 2009. Patterns of field layer invertebrates in successional stages of managed boreal forest: Implications for the declining Capercaillie Tetrao urogallus L. population. Forest Ecology and Management 257: 600-607.

Miettinen, J., Helle, P., Nikula, A. \& Niemelä, P. 2008. Largescale landscape composition and capercaillie (Tetrao urogallus) density in Finland. Annales Zoologici Fennici 45: 161-173.

Miettinen, J., Helle, P., Nikula, A. \& Niemelä, P. 2009. Changes in landscape-scale habitat selection of capercaillie (Tetrao urogallus) in managed north-boreal forest. Silva Fennica 43: 595-608.

Miettinen, J., Helle, P., Nikula, A. \& Niemelä, P. 2010. Capercaillie (Tetrao urogallus) habitat characteristics in north-boreal Finland. Silva Fennica 44: 235-254.

Mikoláŝ, M., Svitok, M., Tejkal, M., Leitão, P.J., Morrissey, R.C., Svoboda, M., Seedre, M. \& Fontaine, J.B. 2015. Evaluating forest management intensity on an umbrella species: Capercaillie persistence in central Europe. Forest Ecology and Management 354: 26-34.

Millennium Ecosystem Assessment, 2005. Ecosystem and human well-being: Biodiversity synthesis. World Resources Inst., Washington DC.

Muscarella, R., Galante, P.J., Soley-Guardia, M., Boria, R.A., Kass, J.M., Uriarte, M. \& Anderson, R.P. 2014. ENMeval: An $\mathrm{R}$ package for conducting spatially independent evaluations and estimating optimal model complexity for Maxent ecological niche models. Methods in Ecology and Evolution 5: 1198-1205.

Mönkkönen, M., Juutinen, A., Mazziotta, A., Miettinen., K., Podkopaev, D., Reunanen, P., Salminen, H. \& Tikkanen, O.-P. 2014. Spatially dynamic forest management to substain biodiversity and economic returns. Journal of Environmental Management 134: 80-89.

Pakkala, T., Pellikka, J. \& Lindén, H. 2003. Capercaillie Tetrao urogallus - a good candidate for an umbrella species in taiga forest. Wildlife Biology 9: 309-316.

Pearson, R.G., Raxworthy, C.J., Nakamura, M. \& TownsendPeterson, A. 2007. Predicting species distributions from small numbers of occurrence records: a test case using cryptic geckos in Madagascar. Journal of Biogeography 34: 102-117.

Phillips, S.J., Anderson, R.P. \& Schapire, R.E. 2006. Maximum entropy modeling of species geographic distributions. Ecological Modelling 190: 231-259.

Phillips, S.J., Dudík, M. \& Schapire, R.E. 2004. A maximum entropy approach to species distribution modeling. Proceedings of the twenty-first international conference on Machine learning ACM, pp. 83.

Quevedo, M., Bañuelos, M.J. \& Obeso, J.R. 2006. The decline of Cantabrian capercaillie: How much does habitat configuration matter? Biological Conservation 127: 190-200.

R Core Team 2014. R: A language and environment for statistical computing. R Foundation for Statistical Computing, Vienna, Austria.

Ringaby, E. 2014. Tjäder. Bland skogbruk, räver og andre jägere. Malou K Media. (In Swedish)

Rolstad, J. 1991. Consequences of forest fragmentation for the dynamics of bird populations: conceptual issues and the evidence. Biological Journal of Linnean Society 42: 149-163.

Rolstad, E. \& Andersen, J. 2003. Storfugløkologi og skogbehandling. Skogforsk \& Løvenskiold, Nikolai Olsens Trykkeri AS, Kolbotn. (In Norwegian)

Rolstad, J. \& Wegge, P. 1987. Distribution and size of capercaillie leks in relation to old forest fragmentation. Oecologia 72: 389-394.

Rolstad, J. \& Wegge, P. 1989a. Capercaillie population and modern forestry - a case for landscape ecological studies. Finnish Game Research 46: 43-52.

Rolstad, J. \& Wegge, P. 1989b. Effects of logging on capercallie leks. Scand. Journal of Forest Research, 4: 111-127.

Rolstad, J., Rolstad, E. \& Wegge, P. 2007. Capercaillie Tetrao urogallus lek formation in young forest. Wildlife Biology 13 (Suppl. 1): 59-67.

Saniga, M. 2003. Ecology of the capercaillie (Tetrao urogallus) and forest management in relation to its protection in the West Carpathians. Journal of Forest Science 49: 229-239.

Segura, A., Castaño-Santamaría, J., Laiolo, P. \& Obeso, J.R. 2014. Divergent responses of flagship, keystone and resource-limited bio-indicators to forest structure. Ecological Research 29: 925-936.

Sirkiä, S., Lindèn, A., Helle, P., Nikula, A., Knape, J. \& Lindèn, H. 2010. Are the declining trends in forest grouse populations due to changes in the forest age structure? A case study of capercaillie in Finland. Biological Conservation 143: 1540-1548.

Sirkiä, S., Nikula, A., Helle, P., Lindèn, H., Norrdahl, K., Suorsa, P. \& Valkeajärvi, P. 2011. Contemporary mature forest cover does not explain the persistence of capercaillie (Tetrao urogallus) lekking areas in Finland. Ornis Fennica 88: 208-216.

Storch, I. 1997. The importance of scale in habitat conservation for an endangered species: the capercaillie in central Europe. Pages 310-330 in J.A. Bissonette, J.A. (ed.). Wildlife and Landscape Ecology: effects of pattern and scale. Springer Verlag, New York.

Stroch, I. 2001. Tetrao urogallus Capercaillie. BWP Updata Vol. 3 (1). Oxford University Press, pp. 1-24.

Suter, W., Graf, R.F. \& Hess, R. 2002. Capercaillie (Tetrao urogallus) and avian biodiversity: Testing the umbrellaspecies concept. Conservation Biology 16: 778-788. 
Thingstad, P.G., Skjeggedal, T. \& Markhus, G. 2003. Humaninduced alteration of two boreal forest landscapes in central Norway, and some possible consequences for avian fauna. Journal for Nature Conservation 11: 157170.

Watson, A. \& Moss, R. 2008. Grouse. The natural history of British and Irish species. HarperCollins Publishers, London.

Wegge, P. \& Rolstad, J. 1986. Size and spacing of capercaillie leks in relation to social behaviour and habitat. Behavioral Ecology and Sociobiology 19: 401-408.
Wegge, P. \& Rolstad, J. 2011. Clearcutting forestry and Eurasian boreal forest grouse: Long-term monitoring of sympatric capercallie Tetrao urogallus and black grouse T. tetrix reveals unexpected effects on their population performances. Forest Ecology and Management 261: 1520-1529.

Wisz, M.S., Hijmans, R.J., Li, J., Peterson, A.T., Graham, C.H., Guisan, A. \& N.P.S.D.W. Group. 2008. Effects of sample size on the performance of species distribution

Received 7 February 2018. Accepted 29 June 2018

Supplementary file, Figure S1:

https://boap.uib.no/index.php/ornis/article/view/1465/2526 